\title{
Primates and its relationship with yellow fever
}

\begin{abstract}
The relationship between humans and wild animals is an ancient problem which is increasing due to the fast population growth, constructing roads, bridges, and invading the natural habitats of these animals. Problems like this are more evident when association of disease with wildlife occurs, such as the case of yellow fever in tropical countries. Primates are sensitive to yellow fever and they are suffering from human violence due to the lack of information about this disease, i.e., primates are being killed by humans because humans think that primates could be spreading the disease. However, primates do not present this condition. Then, the aim this work is to comment about the relation human-wildlife (primates, in specific) in relation to yellow fever. In short, to preserve the wildlife and, mainly, primates, actions from society and government should be implemented to provide information about yellow fever and to preserve primates.
\end{abstract}

Keywords: Primates, Humans, Wildlife conflict, Yellow fever, Animals
Volume 3 Issue 2 - 2018

\author{
Roqueline AGMF Aversi-Ferreira, ${ }^{1,2}$ Karolyne \\ Cordeiro-de-Oliveira, ${ }^{3}$ Gezianne Lopes de \\ Freitas, ${ }^{3}$ Emmanuel Freitas-Ferreira, ${ }^{3}$ Tales A \\ Aversi-Ferreira $^{3}$ \\ 'College of Nutrition, University of Alfenas, Brazil \\ ${ }^{2}$ Department of Physiology, University of Toyama, Japan \\ ${ }^{3}$ Laboratory of Biomathematics, Federal University of Alfenas, Brazil
}

Correspondence: Tales Alexandre Aversi-Ferreira, PhD, Rua Gabriel Monteiro da Silva, 700 Centro, block N, University of Alfenas, Department of Anatomy, Alfenas, Minas Gerais, 37I3000I, Brazil, Tel +5535370I 9564,

Email aversiferreira@gmail.com

Received: February 15, 2018 | Published: March 02, 2018

\section{Opinion}

The beginning of urbanization with the accelerated increasing of the number of cities and consequently the population in the last centuries Hobbs ${ }^{1}$ including the construction of highways, bridges, generated a constant destruction of the natural habitats of wild animals, in addition to deforestation and other ecological consequences as the increase of Arbovirus populations Czech et al. ${ }^{2}$ Vasconcelos et al. ${ }^{3}$ Grimm et al. ${ }^{4}$ since the human-wildlife conflict is as ancient as civilization Soulsbury \& White, ${ }^{5}$ Anand \& Radhakrishna. ${ }^{6}$ The proximity of some cities with forest or part of ancient ones and the preservation of some part of forests in parks and preservation areas in cities approximate humans to the wild animals, and the constant relationship between humans and urban vertebrate such as birds (sparrows, pigeons, crows), rats, skunks, bats, some primates, has generated some kind of ecological relation Markovchick-Nicholls ${ }^{7}$ in which humans supply part or total feed to these animals Clucas \& Marzluff. ${ }^{8}$ Some wild animals have no tendency to accept urban life Lowry Lill \& Wong9 and remain in the green area where, for some reason, increase stress and violence among groups to keep or to obtain new territories due to the decrease of their habitats Finn \& Stephens, ${ }^{10}$ including primates Ditchkoff \& Saalfeld et al. ${ }^{11}$ Bicca-Marques \& Freitas. ${ }^{12}$ This proximity seems to be ecologically disadvantageous for wild animals Messmer, ${ }^{13}$ nevertheless, the clear advantage to obtain food. However, humans also feel discomfortable in living close some animals considered plagues Clucas \& Marzluff, ${ }^{8}$ mainly for rural habitants Messmer. ${ }^{13}$

The humans-wild animals relationship generates many consequences in many aspects such as ecology, behavior, Parasitology, pathology, since the consequences of these interactions are unpredictable Messmer ${ }^{13}$ because, inter alia, the number of wild animals being used as companions has increased Grant ${ }^{14}$ and the number of accidents involving these animals has also increased Rowden. ${ }^{15}$ Specifically in relation to primates, most prefers forests in habitats usually far from humans, indeed, $90 \%$ of non-human primates are dependent on tropical forests Isabirye-Basuta \& Lwanga, ${ }^{16}$ and as occur with other animals, the proximity with humans generates disadvantages and some benefits. Specifically for primates, an important problem associate to them and involved in the humanswildlife relationship is the yellow fever, a disease that affects humans in different cycles, the sylvatic for the primates and urban for humans Costa et al. ${ }^{17}$ in fact, most vertebrates that host the yellow fever virus are primates, including humans Herve et al. ${ }^{18}$ Monath, ${ }^{19}$ Vasconcelos. ${ }^{20}$

The relationship between humans and primates in urban areas is, in ecological terms, recent, therefore, to establish these relations will take time Odum ${ }^{21}$ because wild animals coexist better in the wild habitat, including the cycle of diseases and the cycle of sylvatic yellow fever in primates is an example Aragao. ${ }^{22}$ Indeed, repeated epidemic cycles of yellow fever have been reported in Brazil since long time ago and almost always using primates as epidemic biomarker due to their deaths Bicca-Marques \& Freitas. ${ }^{12}$ Indeed, cycles of sylvatic transmission between monkeys and arboreal mosquitoes occur in Africa, ${ }^{23}$ Asia and South America, with recent outbreak present in these continents Wasserman et al. ${ }^{24}$

These relations among these regions is historically linked as consequence of the slave trade, but is accepted that the yellow fever was originated in Africa. In the humans-wildlife association, the cycle of yellow fever plays an important role for the primates' survivor. The non-scientific information about primates being potential amplifiers of the disease has led many farmers and some more exalted individuals of the population to kill these animals using firearms or poisons with the intention of avoiding the yellow fever propagation, according to the press, Rodrigues ${ }^{23}$ not counting the aggressions and intentional maltreatment that primates are suffering from the population due to lack of correct information Vale \& Prezoto. ${ }^{25}$ However, primates keep the disease from 2 to 6 days and die or acquire definitive immunity, but this time is not enough to make them amplifiers of this disease 
Hervé et al. ${ }^{18}$ Bicca-Marques \& Freitas. ${ }^{12}$ The intention of this opinion article is not to deepen the progress of yellow fever or to discuss the development of this disease in primates, but rather to draw attention to the possible devastation in the lives of these primates who have been forced to live close to humans due to the destruction of their natural habitats (see comments above). It is evident that human beings in the organized society are responsible for the destruction of natural habits of wild animals and the proximity between primates and humans generates suffering to these animals, then, it is reasonable for the rational and responsible part of this relationship to fix the problem caused

\section{Conclusion}

In this way, government and society programs that protect animals are necessary to make people aware and avoid violence against primates and other animals. Programs for the transfer of primates to areas far from civilization or to reserve forests are actions necessary to preserve the life of these animals. Primates are the living history of evolution and human behavior and need special attention to be preserved from the indiscriminate destruction generated by the ignorance of the correct information, and presently, in some countries like Brazil where the primate variety is large, primates have been indiscriminately killed by the population due to the recent outbreak of yellow fever.

\section{Acknowledgements}

None.

\section{Conflict of interest}

The authors declare no financial interest or any conflict of interest for the purpose of this work.

\section{References}

1. Hobbs F, Stoops N. Demographic Trends in the 20th Century. Census 2000 Special Reports. 2002; 163p.

2. Czech B, Krausman PR, Devers PK. Economic associations among causes of species endangerment in the United States. Bio Science. 2000;50(7):593-601.

3. Vasconcelos PFC, Travassos da Rosa APA, Rodrigues SG, et al Inadequate management of natural ecosystem in the brazilian amazon region results in the emergence and reemergence of arboviruses. $\mathrm{Cad}$ Saúde Publica. 2001;17 Suppl:155-164.

4. Grimm NB, Faeth SH, Golubiewski NE, et al. Global change and the ecology of cities. Science. 2008;319(5864):756-760.

5. Soulsbury CD, White PCL. Human-wildlife interactions in urban areas: a review of conflicts, benefits and opportunities. Wildlife Research 2016;42(7):541-553.

6. Anand S, Radhakrishna S. Investigating trends in human-wildlife conflict: is conflict escalation real or imagined. Journal of Asia-Pacific Biodiversity. 2017;10(2):154-161.
7. Markovchik-Nicholls LM, Regan HM, et al. Relationships between human disturbance and wildlife land use in urban habitat fragments. Conserv Biol. 2007;22(1):99-109.

8. Clucas B, Marzluff JM. Cloupled relationships between humans and other organisms. In: Niemelä J \& Breuste JH, et al. editors. Oxford University Press, UK. 2001; pp. 135-147.

9. Lowry $\mathrm{H}$, Lill A, Wong BB. Behavioural responses of wildlife to urban environments. Biol Rev Camb Philos Soc. 2013;88(3):537-549.

10. Finn HC, Stephens NS. The invisible harm: land clearing is an issue of animal welfare. Wildlife Research. 2017;44(5):377-391

11. Ditchkoff SS, Saalfeld ST, Gibson CJ. Animal behavior in urban ecosystems: modifications due to human-induced stress. Urban Ecosystem. 2006;9(1):5-12

12. Bicca-Marques JC, Freitas DS. The role of monkeys, mosquitoes, and humans in the occurrence of a yellow fever outbreak in a fragmented landscape in south Brazil: protecting howler monkeys is a matter of public health. Trop Cons Science. 2010;3(1):78-89.

13. Messmer TA. Human-wildlife con icts: emerging challenges and opportunities. Human-Wildlife Conflicts. 2009;3(1):10-17.

14. Grant RA, Montrose VT, Wills AP. Exnotic: Should We Be Keeping Exotic Pets. Animals (Basel). 2017;7(47):1-11.

15. Rowden PJ, Steinhardt DA, Sheehan MC. Road crashes involving animals in Australia. Accid Anal Prev. 2008;40(6):1865-1871.

16. Isabirye-Basuta GM, Lwanga JS. Primate populations and their interactions with changing habitats. Int J Primatol; 2008;28(1):35-48.

17. Costa ZGA, Elkhoury ANM, Romano APM. Historical development and evolution of epidemiological surveillance and control of yellow fever in Brazil. Rev Pan-Amaz Saude. 2011;2(1):11-16.

18. Hervé JP. Ecologia da febre amarela silvestre no Brasil. Rev Fund Sesp.1986;31(2):131-134.

19. Monath TP. Yellow fever: un update. Lancet Infec Dis. 2001;1(1):11-20.

20. Vasconcelos PFC. Febre amarela. Rev Soc Bras Med Trop. 2003;36(2):275-293.

21. Odum EP. Fundamentals of ecology. WB Saunders, Philadelphia, Pennsylvania, USA: 1974.

22. Aragao HB. Mosquitos e vírus da febre amarela. Men Inst Oswaldo Cruz. 1939;34(4):547-563.

23. Rodrigues R. Although they did not transmit the yellow fever, more than 100 monkeys were killed this year in the State of Rio. Brazil: 2018.

24. Wasserman S, Tambyah PA, Lim PL. Yellow fever cases in Asia: primed for an epidemic. International Journal of Infectious Diseases. 2016;(48):98-103.

25. Vale CA, Prezoto F. It's not the ape's fault: the primates and the yellow fever. Multiverse. 2017;2(1):1-8. 